\title{
Sala de Aula Invertida em aulas de Matemática Financeira Básica no Ensino Médio: reflexões sobre atividades e recursos didáticos digitais
}

\author{
Rosivar Marra Leite Sanches - IFFluminense - rosemarraleite@ hotmail.com \\ Silvia Cristina Freitas Batista - IFFluminense - silviac@iff.edu.br \\ Valéria de Souza Marcelino - IFFluminense -vmarcelino@iff.edu.br
}

\begin{abstract}
Resumo. A Sala de Aula Invertida (SAI) é uma metodologia ativa que propõe o uso do tempo de sala de aula para a realização de atividades diferenciadas, ficando o estudo dos temas como uma ação extraclasse. Este artigo tem como objetivo apresentar atividades e recursos didáticos digitais para a aplicação da SAI em aulas de Matemática Financeira Básica, no Ensino Médio, assim como analisar dados de um teste exploratório desses materiais. A elaboração e a seleção dos materiais tiveram por base critérios da literatura e a Teoria da Aprendizagem Significativa. Posteriormente, foi realizado um teste exploratório com professores de Matemática. A pesquisa teve caráter qualitativo e os dados, coletados por observação, questionários e fóruns de discussão, sinalizaram que os materiais estavam adequados e, também, permitiram tecer reflexões sobre o tema.
\end{abstract}

Palavras-chave: matemática financeira, recursos e atividades didáticas, sala de aula invertida, teoria da aprendizagem significativa.

\section{The Flipped classroom in Basic Financial Mathematics lessons in High School: reflections on activities and digital didactic resources}

\begin{abstract}
The Flipped Classroom (FCR) is an active methodology which suggests the use of teaching time to perform different activities, and the study of the subjects outside class action. This article aims to present activities and digital didactic resources for the application of FCR in Basic Financial Mathematics classes in High School, as well as to analyze data from an exploratory test of these materials. The elaboration and selection of the materials were based on literary criteria and the Meaningful Learning Theory. Subsequently, an exploratory test was carried out with Mathematics teachers. The research had a qualitative character and the data, collected by observation, questionnaires and discussion forums, indicated that the materials were adequate and also allowed us to think about the theme.
\end{abstract}

Keywords: meaningful learning theory, financial Mathematics, flipped classroom, resources and didactic activities.

\section{Introdução}

A Matemática Financeira tem especial relevância para a formação das pessoas, contribuindo para a sua qualidade de vida. No entanto, grande parte dos indivíduos adultos não possui conhecimentos básicos sobre finanças, embora a Matemática Financeira faça parte dos currículos escolares (Rebello et al., 2015). Nesse sentido, metodologias de ensino que favoreçam o estudo desse tema, no Ensino Médio, possibilitando entender melhor a sua importância, são relevantes.

A Sala de Aula Invertida (SAI) é uma metodologia que pode trazer contribuições nesse sentido, pois inverte a lógica do ensino tradicional, propondo que o tempo de sala de aula seja destinado à realização de atividades diferenciadas, ficando o estudo dos conteúdos como atividade extraclasse (Valente, 2014).

$\mathrm{Na}$ SAI, o professor prepara o material e o disponibiliza on-line, o aluno assiste e estuda o material, realiza tarefas e há um compartilhamento virtual de informações entre 
professor e alunos (Schmitz, 2016). De acordo com Valente (2014), o material on-line é variado, composto por vídeos e outros recursos tecnológicos como animações, simulações, laboratório virtual, entre outros. Posteriormente, em sala de aula, os alunos desenvolvem atividades práticas ou projetos voltados para a resolução de problemas, o que pode acontecer de forma individual ou coletiva, sob a orientação do professor que passa a atuar como mediador (Schmitz, 2016).

Nesse cenário, o presente artigo tem como objetivo apresentar um conjunto de atividades e recursos didáticos digitais para a aplicação da SAI em aulas de Matemática Financeira Básica, no Ensino Médio, bem como analisar dados de um teste exploratório desses materiais.

A elaboração e a seleção dos materiais foram baseadas em critérios sobre a SAI, identificados na literatura, e na Teoria da Aprendizagem Significativa (TAS), de David Ausubel. Considera-se que a TAS pode orientar ações no contexto da SAI, uma vez que essa metodologia ativa tem como princípio básico a predisposição do aluno para aprender, o que implica o seu protagonismo (Baldez et al., 2017). Após as etapas de desenvolvimento e seleção de recursos digitais e de elaboração das atividades, foi realizado um teste exploratório desses materiais. Para tanto, foi promovido o minicurso "Sala de Aula Invertida: análise de recursos para Matemática Financeira Básica", em novembro de 2018, com 20 horas de duração, tendo como participantes oito professores que ministravam Matemática, em 2018, na rede pública do Estado do Rio de Janeiro.

A pesquisa seguiu uma abordagem qualitativa e os dados foram coletados por meio de observação, de questionários e de fóruns de discussão on-line. Os dados levantados permitiram observar que os materiais estavam adequados aos seus propósitos e diversos aspectos sobre o tema foram evidenciados, tais como a importância de que os recursos sejam motivadores e de que as atividades incentivem o senso crítico. Esclarece-se que o estudo descrito neste artigo faz parte de uma pesquisa mais ampla, que busca investigar a contribuição de uma proposta pedagógica, apoiada na metodologia SAI, desenvolvida a partir dos princípios da TAS e destinada ao estudo de Matemática Financeira Básica, no Ensino Médio.

Tendo em vista o exposto, este artigo encontra-se estruturado em quatro seções, além desta introdução: a seção 2 traz uma discussão sobre aspectos relativos a atividades e recursos didáticos digitais para a SAI, associada a concepções da TAS, tendo por base a literatura da área. Nas seções 3 e 4, respectivamente, descrevem-se os procedimentos metodológicos adotados e analisam-se os resultados obtidos. Por fim, a seção 5 apresenta algumas considerações sobre o trabalho realizado.

\section{Atividades e recursos digitais para a SAI: aspectos gerais segundo a TAS}

A TAS é uma teoria que considera como aprendizagem significativa aquela caracterizada pela interação entre conhecimentos prévios, que passam a ter novos significados, e os conhecimentos novos, que ganham relevância para o sujeito (Moreira, 2012). Segundo Moreira e Massini (1982), conhecimentos prévios são conceitos relevantes, pré-existentes na estrutura cognitiva do indivíduo, que facilitam a aprendizagem de novos conceitos. Segundo estes autores, Ausubel usou as nomenclaturas subsunçor ou ideia-âncora como sinônimos para conhecimento prévio.

Dois conceitos fundamentais da TAS são diferenciação progressiva e reconciliação integradora. O primeiro é baseado no fato de que grande parte da aprendizagem, sua consequente retenção e organização são ações hierárquicas por natureza. Portanto, a organização do conteúdo deve ocorrer de cima para baixo em termos de abstração, generalização e inclusão, partindo dos conceitos de maior inclusão para os de menor (Ausubel, 2003). O segundo consiste na resolução dos conflitos entre 
os significados dos conceitos, por meio da análise das relações entre estes, indicando-se semelhanças e diferenças e reconciliando-se inconsistências reais ou aparentes, com o objetivo de combinar ideias similares (Ausubel, 2003).

O material a ser utilizado para fins didáticos deve ser potencialmente significativo, para facilitar a aprendizagem significativa, mas, apesar da importância do material, o foco principal encontra-se nas pessoas, o que torna essencial a figura do professor (Moreira, 2012). Um dos instrumentos facilitadores da aprendizagem significativa é o organizador prévio. Organizadores prévios são materiais introdutórios com o objetivo de gerar os subsunçores que o aluno não dispõe, de modo que estes apareçam antes da apresentação do conteúdo (Moreira, 2012).

A SAI, por sua vez, é uma metodologia na qual ocorre a inversão entre a sala de aula presencial e a residência ou outro local fora da escola, onde o material é estudado. O espaço da sala de aula é utilizado para o aprofundamento do conteúdo e eliminação das dúvidas apresentadas pelo aluno (Pavanelo; Lima, 2017).

Teorias de aprendizagem centradas no aluno são essenciais para entender o conceito da SAI, que é constituída, basicamente, por duas componentes: uma que necessita de interação humana, em sala de aula, e outra que é desenvolvida por meio do uso das tecnologias digitais (TD) nas atividades on-line (Bishop; Velerger, 2013). Neste estudo, defende-se a TAS como um aporte teórico adequado para a SAI, a partir das convergências descritas no Quadro 1.

Quadro 1 - Convergências entre TAS e SAI: atividades e recursos didáticos

\begin{tabular}{|c|c|c|}
\hline $\begin{array}{l}\text { Elementos } \\
\text { Analisados }\end{array}$ & TAS & SAI \\
\hline $\begin{array}{c}\text { Recursos } \\
\text { introdutórios }\end{array}$ & Organizadores prévios. & $\begin{array}{l}\text { Recordar de forma colaborativa antes do } \\
\text { momento presencial. }\end{array}$ \\
\hline $\begin{array}{l}\text { As situações- } \\
\text { problema dão } \\
\text { sentido a novos } \\
\text { conhecimentos }\end{array}$ & $\begin{array}{l}\text { Situações novas requerem novas } \\
\text { soluções, podendo funcionar como } \\
\text { organizadores prévios. }\end{array}$ & $\begin{array}{l}\text { Aluno como protagonista } \\
\begin{array}{l}\text { realizando } \\
\text { atividades voltadas à à } \\
\text { experimentação e resolução de problemas. }\end{array}\end{array}$ \\
\hline $\begin{array}{l}\text { Problemas } \\
\text { propostos }\end{array}$ & Diferenciação progressiva. & $\begin{array}{l}\text { Atividades em diferentes níveis de } \\
\text { dificuldades sempre com a efetiva ajuda do } \\
\text { professor. }\end{array}$ \\
\hline $\begin{array}{l}\text { Organização do } \\
\text { material }\end{array}$ & $\begin{array}{l}\text { - Do geral para o específico, } \\
\text { utilizando os subsunçores disponíveis } \\
\text { (diferenciação progressiva); } \\
\text { - Deve permitir análise dos conceitos, } \\
\text { de forma a encontrar similaridades e } \\
\text { diferenças (reconciliação } \\
\text { integradora). }\end{array}$ & $\begin{array}{l}\text { - Estudo do material on-line, organizado em } \\
\text { ordem crescente de dificuldade; } \\
\text {-Atividades presenciais com o } \\
\text { aprofundamento do conteúdo estudado } \\
\text { previamente, confrontando similaridades e } \\
\text { diferenças. }\end{array}$ \\
\hline $\begin{array}{l}\text { Recursos e } \\
\text { Atividades }\end{array}$ & $\begin{array}{l}\text { Os recursos e atividades precisam ser } \\
\text { potencialmente significativos. }\end{array}$ & $\begin{array}{l}\text {-Ênfase na elaboração/seleção dos materiais, } \\
\text { tanto da parte on-line quanto da presencial; } \\
\text {-As atividades devem ser contextualizadas, } \\
\text { partindo da realidade do aluno. }\end{array}$ \\
\hline $\begin{array}{l}\text { Papel do } \\
\text { Professor }\end{array}$ & $\begin{array}{l}\text {-Propor as situações-problema, } \\
\text { cuidadosamente selecionadas; } \\
\text { - Organizador do material de ensino; } \\
\text {-Mediador da captação de } \\
\text { significados. }\end{array}$ & $\begin{array}{l}\text {-Mediador ou facilitador dos processos de } \\
\text { ensino e aprendizagem; } \\
\text { - Responsável pela organização do material da } \\
\text { aula on-line e presencial; } \\
\text { - Atua motivando e auxiliando o aluno durante } \\
\text { o processo, definindo a linguagem e os } \\
\text { significados adotados pelo grupo. }\end{array}$ \\
\hline
\end{tabular}

Fonte: Elaboração própria a partir de Moreira (2012), Pavanelo e Lima (2017), Rosa et al. (2016) e Valente (2014).

De acordo com Christensen et al. (2013), a SAI não modifica radicalmente a estrutura escolar, apenas introduz uma solução que mistura a sala de aula tradicional 
com as TD, com o objetivo de potencializar os recursos disponíveis para a prática docente, dependendo da intencionalidade do professor. As regras básicas para se inverter a sala de aula, segundo Valente (2014), são: i) as atividades em sala de aula são planejadas de modo a levar o aluno a aplicar e ampliar o material estudado on-line; ii) os alunos recebem feedback após a realização das atividades presenciais; iii) as atividades on-line e as presenciais são pontuadas; iv) os materiais tanto presenciais quanto on-line são extremamente bem planejados.

As atividades on-line, extraclasse, fornecem ao professor uma visão daquilo que os alunos estão tendo mais dificuldade. Na parte presencial, os conteúdos estudados online são retomados e as dúvidas são esclarecidas, por isso os materiais precisam ser bastante diferenciados. Em relação aos recursos digitais utilizados na SAI, Schmitz (2016) elenca alguns, dentre os quais, vídeos e videoaulas; lousas digitais; fóruns, wikis, recursos educacionais abertos e redes sociais digitais.

Uma característica essencial da SAI é a autonomia do aluno, o que se torna um grande desafio, pois, em geral, os estudantes não são incentivados nesse sentido (Milhorato; Guimarães, 2016). O aluno assume o papel de protagonista, sendo responsável por sua aprendizagem. O professor assume o papel de mediador, aquele que organiza as informações, permitindo ao aluno transformá-las em conhecimento.

No Quadro 2, tendo por base quatro pesquisas relacionadas ao presente estudo, são apresentadas algumas vantagens e dificuldades associadas à aplicação da SAI, sendo algumas destas relativas a recursos e atividades.

Quadro 2 - Vantagens e Dificuldades da SAI

\begin{tabular}{|c|c|c|}
\hline Trabalhos & Vantagens & Dificuldades \\
\hline $\begin{array}{l}\text { Milhorato } \\
\text { e } \\
\text { Guimarães } \\
\text { (2016) }\end{array}$ & $\begin{array}{l}\text { Protagonismo do aluno, interatividade e } \\
\text { colaboração; flexibilidade de tempo e } \\
\text { local; estímulo à investigação; } \\
\text { desenvolvimento da autonomia e da } \\
\text { responsabilidade; possibilidade de } \\
\text { trabalhar as dificuldades dos alunos. }\end{array}$ & $\begin{array}{l}\text { Falta de conhecimentos prévios dos alunos, de } \\
\text { tempo para os que trabalham e de disciplina em } \\
\text { relação aos estudos; necessidade de domínio das } \\
\text { ferramentas tecnológicas e de Internet de boa } \\
\text { qualidade. }\end{array}$ \\
\hline $\begin{array}{l}\text { Santos et } \\
\text { al. }(2017)\end{array}$ & $\begin{array}{l}\text { Melhoria da aprendizagem; aumento da } \\
\text { qualidade do estudo e possibilidade de } \\
\text { novas formas de aprender. }\end{array}$ & $\begin{array}{l}\text { Ajuste do tempo necessário para que os alunos } \\
\text { realizem as atividades propostas, o que requer } \\
\text { planejamento adequado por parte do professor; } \\
\text { preparação de atividades que sejam, de fato, } \\
\text { contextualizadas e problematizadoras, para que } \\
\text { o uso de recursos tecnológicos não seja o maior } \\
\text { diferencial entre aulas com a SAI e as com } \\
\text { abordagens tradicionais. }\end{array}$ \\
\hline $\begin{array}{l}\text { Rangel et } \\
\text { al. (2018) }\end{array}$ & $\begin{array}{l}\text { Participação mais ativa dos alunos nas } \\
\text { atividades e maior colaboração; } \\
\text { otimização do tempo em sala de aula } \\
\text { para trabalhar o conteúdo de forma mais } \\
\text { eficaz. }\end{array}$ & $\begin{array}{l}\text { Falta de motivação de alguns alunos para } \\
\text { estudar os materiais e responder às atividades } \\
\text { propostas no ambiente virtual; tempo necessário } \\
\text { para a elaboração e seleção de materiais } \\
\text { didáticos; gerenciamento e planejamento de } \\
\text { estratégias em sala de aula que possam ajudar } \\
\text { alunos com dificuldades e, também, estimular } \\
\text { os mais avançados. }\end{array}$ \\
\hline $\begin{array}{l}\text { Valério } \\
\text { e } \\
\text { Moreira } \\
(2018)\end{array}$ & $\begin{array}{l}\text { Avanços nas relações entre professor- } \\
\text { aluno e entre aluno-aluno; trabalho } \\
\text { individualizado e adequado ao ritmo dos } \\
\text { alunos; desenvolvimento de habilidades } \\
\text { comunicativas, do pensamento crítico e } \\
\text { de resolução de problemas; melhoria no } \\
\text { ambiente de sala de aula, no desempenho } \\
\text { e frequência dos estudantes. }\end{array}$ & $\begin{array}{l}\text { Dificuldades de adaptação à metodologia por } \\
\text { parte de alguns alunos, devido à exigência de } \\
\text { responsabilidade e autonomia. Tempo } \\
\text { necessário para o professor reestruturar o plano } \\
\text { de trabalho e para encontrar materiais } \\
\text { adequados ao tipo de enfoque desejado. }\end{array}$ \\
\hline
\end{tabular}

Fonte: Elaboração própria, a partir dos trabalhos analisados. 
A partir das dificuldades mencionadas no Quadro 2, observa-se que o tempo necessário à elaboração e à seleção de materiais para a SAI é um aspecto a ser considerado na adoção dessa proposta. Como esses materiais devem ser bem adequados ao planejamento metodológico, ações direcionadas aos mesmos devem ser realizadas com cuidado e atenção. As estratégias para as atividades on-line devem considerar o conhecimento tecnológico dos alunos e a qualidade de Internet que estes possuem; as presenciais, entre outros aspectos, devem levar em consideração que alguns alunos, ou grupos, apresentam mais facilidade do que outros e é preciso que o professor atue de forma a não prejudicar o desenvolvimento de ninguém.

As vantagens apontadas no Quadro 2 são coerentes com os princípios da TAS, uma vez que, por exemplo, essa teoria ressalta que a aprendizagem só ocorre se houver significado no conteúdo, colaboração no processo e predisposição do aluno para aprender, o que implica uma participação mais ativa e o seu protagonismo.

Os aspectos abordados nesta seção foram considerados na elaboração e na seleção dos materiais do presente estudo. Estes foram experimentados em um teste exploratório promovido com professores de Matemática, como detalhado nas duas próximas seções.

\section{Aspectos metodológicos}

O teste exploratório realizado com professores teve por objetivo experimentar e avaliar materiais com potencial para serem utilizados como recursos pedagógicos na aplicação da SAI, em aulas de Matemática Financeira Básica. A pesquisa, de natureza qualitativa, foi do tipo exploratória, pois buscou esclarecer conceitos e ideias, tendo em vista a formulação de hipóteses mais claras para estudos posteriores (Gil, 2008).

Para tanto, foi organizado o minicurso "Sala de Aula Invertida: análise de recursos para Matemática Financeira Básica", com 20h (6h presenciais e $14 \mathrm{~h}$ a distância). A parte presencial teve três encontros, com $2 \mathrm{~h}$ cada um, realizados em 08,22 e 29 de novembro de 2018. Os participantes foram oito professores que ministravam Matemática em um Colégio Estadual do Estado do Rio de Janeiro, selecionado por ser o local de atuação da primeira autora deste artigo.

Os dados foram coletados por meio de: i) observação da participação dos professores nos encontros presenciais; ii) três questionários; iii) registros nos fóruns de discussão. Os três questionários buscaram, respectivamente: i) levantar dados que permitissem traçar um breve perfil dos professores participantes, em termos de formação acadêmica e atuação profissional; ii) captar a percepção dos professores sobre os dois aplicativos para dispositivos móveis adotados como recursos didáticos para estudo do tema: Matemática Financeira ${ }^{1}$ e Wisecash $^{2}$; iii) verificar a opinião dos professores sobre a relevância do uso pedagógico dos materiais experimentados e sobre a aplicabilidade da metodologia SAI e, também, captar críticas e sugestões. Nos questionários, foram utilizadas perguntas com campos para comentários.

No minicurso, utilizou-se o ambiente virtual de aprendizagem $S c h o o l o g y^{3}$, em sua versão gratuita. Este ambiente é baseado em computação em nuvem, oferece recursos adequados para o gerenciamento de ações pedagógicas e possui uma interface muito parecida com o de uma rede social, fatores que justificam sua escolha. No Schoology, foram disponibilizados os materiais a serem experimentados e foram abertos cinco fóruns nos quais os participantes poderiam registrar suas avaliações.

Os dados coletados foram analisados segundo o referencial teórico adotado. Destaca-se que a coleta e a divulgação dos resultados desta pesquisa foram autorizadas pelos professores, a partir da assinatura de termo de consentimento para tal fim.

Os materiais utilizados no minicurso foram elaborados e selecionados de acordo com os fundamentos da TAS e da SAI e serão aplicados em uma proposta pedagógica a 
ser experimentada com alunos do Ensino Médio. Assim, os professores analisaram também os instrumentos de coleta de dados a serem aplicados aos alunos do Ensino Médio: questionários e o pré e o pós-teste. Nas subseções seguintes, descrevem-se, respectivamente, os materiais das partes on-line e presencial da proposta com a SAI.

\subsection{Recursos e Atividades: parte on-line (extraclasse)}

- Vídeo introdutório: elaborado para fazer uma apresentação inicial do material on-line e motivar os alunos do Ensino Médio. Para tanto, utilizou-se o software on-line Powtoon $^{4}$, que serve para criação de apresentações no formato de slides e vídeos animados. A escolha desse software deu-se pelo fato deste oferecer, em sua versão gratuita, variados recursos audiovisuais, permitir a publicação do vídeo no seu próprio site e a utilização do link;

- Oito videoaulas:

- Três desenvolvidas com o Powtoon e destinadas a explicar tópicos relativos a conceitos de Educação Financeira: "O que é Educação Financeira?"; "A Temida Inflação" e "Cartão de Crédito";

- Cinco organizadas como apresentações de slides no PowerPoint e, em seguida, gravadas no software Camtasia e editadas no MovieMaker: quatro para Matemática Financeira e uma para Educação Financeira. Os temas foram Porcentagem, Juros Simples, Juros Compostos (duas videoaulas) e Investimentos. A adoção de formatos diferenciados para as videoaulas objetivou contribuir para que o uso desses recursos não se tornasse monótono. Os programas PowerPoint, Camtasia e MovieMaker foram selecionados em função da facilidade de uso. Durante a elaboração das videoaulas de Matemática Financeira, notou-se a necessidade de esclarecer certos aspectos relacionados a investimentos, do que decorreu o desenvolvimento da videoaula sobre esse tema de Educação Financeira.

- Vídeo "Leandro Karnal - Educação Financeira", disponível no Youtube : selecionado para promover uma reflexão crítica sobre o tema Educação Financeira;

- Três listas com problemas contextualizados, considerando os princípios da TAS e da SAI, com o objetivo de aplicar os conteúdos estudados nas videoaulas e estabelecer a relação desses conhecimentos com o cotidiano. Os problemas de cada lista foram discutidos e corrigidos em sala de aula, para eliminação de dúvidas. A lista 1 trazia problemas sobre Porcentagem, a 2 sobre Juros Simples e a 3 sobre Juros Compostos.

\subsection{Recursos e Atividades: parte presencial}

- Aplicativo Matemática Financeira: selecionado para ser utilizado em sala de aula, pelos alunos do Ensino Médio, para verificar se os cálculos de Juros Simples e Compostos, realizados manualmente na resolução das listas 2 e 3, estariam corretos. Objetiva-se que os exercícios sejam conferidos e, caso necessário, refeitos de forma colaborativa, e, além disso, que o aluno aprenda a manusear um aplicativo que auxilia no cálculo de juros e perceba que este pode ser utilizado em situações do cotidiano. O aplicativo Matemática Financeira foi selecionado, pois, além de permitir os cálculos, traz fórmulas com uma breve descrição do conteúdo;

- Três situações-problema elaboradas com níveis crescentes de complexidade, da seguinte forma: i) situação-problema 1: aborda o conteúdo de Porcentagem, propondo o cálculo do lucro obtido em um empreendimento e, para tanto, requer uma pesquisa na Internet sobre o produto a ser vendido, que poderá ser realizada por meio dos smartphones dos próprios alunos; ii) situação-problema 2: trata do conteúdo Juros Simples, solicitando que o aluno crie um problema, a partir dos estudos realizados; iii) situação-problema 3: referente ao assunto Juros Compostos em uma situação real sobre cheque especial; 
- Proposta de um seminário no qual cada grupo de alunos deverá apresentar um dos seguintes temas: i) "A Poupança e o Planejamento de uma Compra Futura"; ii) "Como Funciona um Consórcio de Veículos: Ênfase nas Taxas de Administração Cobradas"; iii) "O Uso Correto do Cartão de Crédito"; iv) "Preciso Fazer uma Previdência Privada para Garantir minha Aposentadoria?"; v) "Na Hora de Comprar: Compro à Vista, Uso o Cartão ou Financio no Boleto?". A proposta do seminário busca dar autonomia aos alunos, na medida em que o professor deixa a organização do material da aula sob a responsabilidade destes. Após a apresentação dos grupos, o professor deverá fazer as ponderações necessárias, organizando as informações;

- Oficina de Controle de Gastos: proposta que busca estimular a gestão eficiente das finanças pessoais. Para tanto, será estipulado um salário mensal fictício que deverá ser gasto com: i) despesas pessoais, tais como lazer, estética, vestuário, crédito para celular, entre outros; ii) despesas familiares, sugerindo que o aluno ajude nas contas de casa, como por exemplo, assumindo a conta de luz ou de água, para que este tenha uma visão desse tipo de despesa; iii) despesas com os estudos, tais como compra de materiais de papelaria, aquisição de cópias, livros, entre outros; iv) poupança, com a orientação de que parte do valor do salário estipulado deverá ser guardado. Nessa proposta, adota-se o aplicativo de controle de gastos Wisecash para simular o gerenciamento das despesas mensais, durante o bimestre no qual a metodologia for aplicada. O Wisecash foi selecionado pela facilidade de uso.

Especificamente para o minicurso com os professores, foram elaboradas apresentações de slides, explicando o objetivo da pesquisa e aspectos teóricos da TAS e da SAI. Também foi apresentada uma sequência didática, elaborada em estudos prévios da primeira autora deste artigo, na qual o tema "Introdução às Matrizes" foi abordado de acordo com a metodologia SAI. Objetivou-se, dessa forma, facilitar o entendimento da proposta da SAI. Como o minicurso faz parte de uma pesquisa mais ampla, os professores também avaliaram os instrumentos de coleta de dados (questionários, pré e pós-teste) que serão utilizados na aplicação da proposta com alunos do Ensino Médio.

Para a análise dos dados obtidos, promovida na seção seguinte, os professores foram nomeados P1, P2, ..., P8.

\section{Descrição e Análise dos Dados}

Os dados do primeiro questionário permitiram observar que: i) em relação à formação acadêmica, todos os professores eram licenciados em Matemática e tinham especialização, sendo P4 também Bacharel em Ciências da Computação, mestre e doutora em Modelagem Computacional; ii) o tempo de docência atuando com Matemática variava entre 10 e 30 anos; iii) quanto ao nível de ensino em que atuavam: P2 e P7 - apenas no Ensino Fundamental; P1, P3, P5, P6 e P8 - Fundamental e Médio; P4 - Médio, Fundamental e Superior; iv) em relação às disciplinas que estavam lecionando na época da pesquisa, além da disciplina Matemática: P5, P6 e P8 Resolução de Problemas Matemáticos (RPM); P3 - RPM e Física; P4 - RPM e disciplinas em Curso Superior. Dessa forma, considerou-se que os professores possuíam um perfil adequado para o objetivo da pesquisa.

No primeiro encontro do minicurso, inicialmente, foram exibidos os recursos elaborados especificamente para minicurso, mencionados na seção anterior, tendo em vista esclarecer a proposta pedagógica da qual os recursos didáticos e atividades fazem parte. Em seguida, ocorreu uma discussão sobre a SAI, na qual os participantes exprimiram suas dúvidas quanto à realização de atividades on-line antes do momento presencial. De acordo com suas experiências, os alunos são reticentes para realizar tarefas extraclasse, o que é ratificado pela literatura, uma vez que uma das desvantagens 
da SAI apontadas no referencial teórico é a falta de motivação dos estudantes para realizar estudos e tarefas previamente (Rangel et al., 2018).

Também foram apresentadas nesse encontro, as propostas do Seminário e da Oficina de Gastos. Os professores consideraram que a Oficina tem potencial para desenvolver o controle dos gastos pessoais, que os temas para o Seminário são adequados e que o resultado dessas atividades será bastante positivo.

Após serem cadastrados, os professores entraram no ambiente Schoology. Neste, acessaram os instrumentos de coleta de dados a serem utilizados com os alunos do Ensino Médio (questionários, pré e pós-teste) e, também, as listas de exercícios propostas. Os materiais foram explicados, assim como os fóruns para a avaliação destes.

Os professores ressaltaram a importância das listas, do pré-teste e do pós-teste trazerem problemas relacionados à realidade dos alunos e destacaram que essa relação facilita a aprendizagem dos conceitos. P3 afirmou: "Adorei os exercícios, pois apresentam questões contextualizadas favorecendo a aprendizagem significativa". Essa opinião condiz com a visão de Pavanelo e Lima (2017), Rosa et al. (2016) e Valente (2014), que defendem que as atividades na SAI devem ser contextualizadas. Em relação aos questionários, estes foram considerados adequados, pois continham perguntas claras e objetivas, de fácil entendimento para o público-alvo.

No segundo encontro, solicitou-se que os professores acessassem o Schoology, no qual foram disponibilizados as videoaulas e os vídeos, sendo alguns desses materiais apresentados. O fórum para avaliação destes e os links dos aplicativos Matemática Financeira e Wisecash também foram mostrados. Em seguida, foram brevemente apresentados o Powtoon, o Camtasia e o MovieMaker. Nenhum desses programas era conhecido pelos professores. Nesse momento, discutiu-se a importância de que vídeos e videoaulas sejam de curta duração, como sugerido por Pavanelo e Lima (2017). Para o próximo momento presencial, foi solicitado que os professores assistissem aos vídeos e às videoaulas, postassem suas avaliações no fórum on-line e utilizassem os aplicativos.

Os professores, em geral, destacaram que as videoaulas e os vídeos analisados eram objetivos e compactos e que, por utilizarem linguagem simples e adequada ao vocabulário dos alunos, poderiam facilitar a compreensão dos conteúdos. P8 afirmou: "Os vídeos têm linguagem clara, são curtos e, portanto, não são cansativos. O assunto tratado em cada um deles é bem adequado e com certeza contribuirá para os bons resultados junto aos alunos". Moreira (2012) ressalta a importância da linguagem para facilitar a aprendizagem significativa. Além disso, a professora P1 afirmou: "Gostaria de destacar ainda que precisamos aprender investir nossas economias desde cedo em nossa vida, confesso que depois de velha ainda não sei”. Esse depoimento, corrobora a visão de Rebello et al. (2015) quando afirma que grande parte dos adultos brasileiros não tem conhecimentos básicos sobre finanças.

No terceiro e último encontro presencial, foram preenchidos os questionários de avaliação dos aplicativos. As situações-problema foram apresentadas e avaliadas com postagens no fórum on-line e, por fim, foi aplicado o último questionário.

Em relação aos aplicativos, todos os professores consideraram que o uso do Matemática Financeira mostra como a tecnologia pode contribuir para a aprendizagem dos conteúdos e que o Wisecash é uma ferramenta adequada para a proposta. Pavanelo e Lima (2017), Rosa et al. (2016) e Valente (2014) defendem a importância de atividades de experimentação que levem o aluno a exercer o seu protagonismo. $\mathrm{O}$ uso dos aplicativos pode contribuir nesse sentido.

As situações-problema foram consideradas claras, interessantes e contextualizadas, o que, segundo os professores, pode facilitar a compreensão dos conteúdos. Para P7: "As atividades dadas são interessantes, pois envolvem os alunos, de 
uma forma crítica, criativa e participativa. As questões são contextualizadas e isso facilita a compreensão do conteúdo". Destacaram, também, que atividades que levam o aluno a criar os próprios problemas podem possibilitar que os conteúdos estudados sejam aplicados em situações novas, sendo úteis na aprendizagem dos conceitos. Isso, segundo Moreira (2012), corresponde à definição de aprendizagem significativa.

Na visão dos professores, o ambiente Schoology é uma ferramenta interessante, estimulante e motivadora, cinco professores classificaram a sua experiência como ótima e três como boa. A única dificuldade relatada foi utilizá-lo quando a conexão com a Internet estava lenta. Milhorato e Guimarães (2016) chamam a atenção para a necessidade de Internet de boa qualidade para os adeptos da SAI.

De modo geral, os professores afirmaram que os recursos e atividades estavam adequados aos objetivos propostos, tendo em vista o público-alvo em questão, e consideraram possível implementar, com seus alunos, a metodologia SAI.

Os dados levantados no minicurso ratificaram diversos aspectos identificados na literatura da área e permitiram refletir sobre os seguintes aspectos:

- O material precisa ser motivador para que o aluno tenha predisposição para aprender e facilitar a aprendizagem significativa dos conceitos. As videoaulas de Educação Financeira, por exemplo, trazem informações relevantes sobre o assunto, buscando instigar o aluno a querer aprender mais;

- As atividades, tanto da parte on-line quanto da presencial, devem ser contextualizadas. Os exercícios, situações-problemas e demais atividades foram propostos dessa forma, abordando corretamente os conteúdos de Matemática Financeira Básica, em nível adequado para alunos do $3^{\circ}$ ano do Ensino Médio, para que possam ser efetivamente significativos;

- Os recursos didáticos e atividades devem permitir que o docente atue como facilitador dos processos de ensino e aprendizagem. Nesse sentido, exemplos resolvidos, inseridos nas videoaulas, apresentam, adequadamente, as estratégias de raciocínio matemático necessários para o entendimento da resolução;

- Na proposta descrita, a Educação Financeira é utilizada para introduzir a Matemática Financeira e os conteúdos Porcentagem, Juros Simples e Juros Compostos são abordados em ordem crescente de dificuldade, de acordo com a TAS;

- O material precisa fomentar a autonomia do aluno para que este se torne protagonista da construção de seu conhecimento. Por exemplo, as videoaulas favorecem a autonomia do aluno, facilitando a aprendizagem na parte a distância da metodologia.

\section{Considerações Finais}

A revisão bibliográfica ressaltou a relevância da discussão sobre elaboração de materiais para a SAI para que estes sejam significativos e contribuam para a aprendizagem dos conteúdos trabalhados. Na percepção dos participantes, o material experimentado foi considerado adequado para a implementação da metodologia SAI em aulas de Matemática Financeira Básica, o que foi determinante para validá-lo.

Destaca-se que metodologia SAI estimula o professor a preparar o seu próprio material, ao invés de utilizar questões e atividades prontas, muitas vezes não condizentes com a realidade do aluno. Esse aspecto requer bastante atenção por demandar tempo e dedicação.

Verificou-se, apesar de não ser o objetivo principal, que a experimentação e avaliação de materiais utilizados como recursos para a SAI impulsionou uma reflexão sobre novas estratégias de ensino, o que pode contribuir para a inovação de práticas pedagógicas. Como trabalhos futuros, pretende-se experimentar e analisar a aplicação da proposta pedagógica elaborada em situação real de ensino, no Ensino Médio. 


\section{Notas de Texto}

${ }^{1}<$ https://play.google.com/store/apps/details?id=br.com.iconeconsult.matematicafinanceira\&hl=pt_B $>$.

${ }^{2}<$ https://play.google.com/store/apps/details?id=com.ecda. $w i s e c a s h>$.

$3<$ https://www.schoology.com/>.

${ }^{4}<$ https://www.powtoon.com/home/>.

${ }^{5}<$ https://www.youtube.com/watch?v=CVMye0k2R7Y>.

\section{Referências}

AUSUBEL, D. P. Aquisição e retenção de conhecimentos: uma perspectiva cognitiva. Lisboa: Plátano, 2003. 243 p.

BALDEZ, A. L. S.; DIESEL A.; MARTINS, S. N. Os Princípios das Metodologias Ativas de Ensino: uma abordagem teórica. Revista Thema, v. 14, n.1, p. 268-288, 2017.

BISHOP, J. L.; VERLEGER, M. A. The Flipped Classroom: A Survey of the Research. In: ASEE ANNUAL CONFERENCE \& EXPOSITION, 120., 2013, Atlanta. Anais... Washington DC: American Society for Engineering Education, 2013. p. 1-18. CHRISTENSEN, C. M.; HORN, M. B.; STAKER, H. Ensino Híbrido: uma Inovação Disruptiva? Uma introdução à teoria dos híbridos. Trad. da Fundação Lemann e Instituto Península, 2013. 52 p.

GIL, A. C. Métodos e Técnicas de Pesquisa Social. São Paulo: Editora Atlas, 2008. MILHORATO, P. R.; GUIMARAES, E. H. R. Desafios e possibilidades da implantação da metodologia sala de aula invertida: estudo de caso em uma Instituição de Ensino Superior privada. Revista de Gestão e Secretariado, v. 7, n. 3, p. 253-276, 2016. MOREIRA, M. A. ¿, Al afinal, qué es aprendizaje siginificativo?. Qurriculum: revista de teoría, investigación y práctica educativa, La Laguna, Espanha, p. 29-56, 2012. MOREIRA, M. A.; MASINI, E. F. S. Aprendizagem significativa: A teoria de David Ausubel. São Paulo: Editora Moraes LTDA, 1982. 112 p.

PAVANELO, E.; LIMA, R. Flipped Classroom: the analysis of an experience in the discipline of Calculus I. Bolema: Boletim de Educação Matemática, v. 31, n. 58, p. 739-759, ago. 2017.

RANGEL, R. dos S.; BATISTA, S. C. F.; PEIXOTO, G. T. B. Sala de Aula Invertida: análise de uma experiência com o ambiente virtual Schoology. Revista Novas

Tecnologias na Educação - RENOTE, v. 16, n. 1, 2018.

REBELLO, A. P.; HARRES, J. B. S.; ROCHA FILHO, J. B. da. Educação financeira: uma proposta pedagógica para alunos do ensino médio politécnico. HOLOS, v. 6, p. 308-314, dez. 2015.

ROSA, C. T. W. da; CAVAlCANTI, J.; PEREZ, C. A. S. Unidade de ensino potencialmente significativa para a abordagem do sistema respiratório humano: estudo de caso. Revista Brasileira de Ensino de Ciência e Tecnologia, v. 9, n. 3, 2016.

SANTOS, A. C. dos; NICOLETE, P. C.; MATTIOLA, N.; SILVA, J. B. da. Ensino Híbrido: relato de experiência sobre o uso de AVEA em uma proposta de Sala de Aula Invertida para o Ensino Médio. Revista Novas Tecnologias na Educação - RENOTE, v. 15, n. 2, 2017.

SCHMITZ, E. X. da S. Sala de aula invertida: uma abordagem para combinar metodologias ativas e engajar alunos no processo de ensino-aprendizagem. Santa Maria, RS: UFSM, 2016. 185 p. Dissertação de Mestrado.

VALENTE, J. A. Blended learning e as mudanças no ensino superior: a proposta da sala de aula invertida. Educar em Revista, n. 4, p. 79-97, 2014.

VALÉRIO, M.; MOREIRA, A. L. O. R. Sete Críticas à Sala de Aula Invertida. Revista Contexto \& Educação, n. 106, p. 215-230, 2018. 